\title{
Similarity in Neuronal Firing Regimes across Mammalian Species
}

\begin{abstract}
Yasuhiro Mochizuki, ${ }^{1}$ CTomokatsu Onaga, ${ }^{1}$ OHideaki Shimazaki, ${ }^{2}$ Takeaki Shimokawa, ${ }^{3}$ Yasuhiro Tsubo, ${ }^{2,4}$ Rie Kimura, ${ }^{5}$ Akiko Saiki, ${ }^{5}$ Yutaka Sakai, ${ }^{5}$ Yoshikazu Isomura, ${ }^{5}$ Shigeyoshi Fujisawa, ${ }^{2}$ Ken-ichi Shibata, ${ }^{6}$ Daichi Hirai, ${ }^{6}$ Takahiro Furuta, ${ }^{6}$ Takeshi Kaneko, ${ }^{6}$ Susumu Takahashi, ${ }^{8}$ Tomoaki Nakazono, ${ }^{8}$ 'Seiya Ishino, ${ }^{9}$ Yoshio Sakurai, ${ }^{8}$ Takashi Kitsukawa, ${ }^{11}$ Jong Won Lee, ${ }^{12}{ }^{-}$Hyunjung Lee, ${ }^{13}$ Min Whan Jung, ${ }^{12,14}$ Cecilia Babul, ${ }^{15}$ @Pedro E. Maldonado, ${ }^{15}$ CKazutaka Takahashi, ${ }^{16}$ Fritzie I. Arce-McShane, ${ }^{16}$ Callum F. Ross, ${ }^{16}$ Barry J. Sessle, ${ }^{18}$ Nicholas G. Hatsopoulos, ${ }^{16,17}$ Thomas Brochier, ${ }^{19}$ Alexa Riehle, ${ }^{19,20}$ Paul Chorley, ${ }^{20}$ Sonja Grün, ${ }^{20,21}$ Hisao Nishijo, ${ }^{22}$ Satoe Ichihara-Takeda, ${ }^{23}$ Shintaro Funahashi, ${ }^{7}$ Keisetsu Shima, ${ }^{24}$ Hajime Mushiake, ${ }^{24}$ Yukako Yamane, ${ }^{11,25}$ Hiroshi Tamura, ${ }^{11,25}$ - Ichiro Fujita, ${ }^{11,25}$ Naoko Inaba, ${ }^{6}$ Kenji Kawano, ${ }^{6}$ Sergei Kurkin, ${ }^{26}$ Kikuro Fukushima, ${ }^{26}$ Kiyoshi Kurata, ${ }^{27}$ Masato Taira, ${ }^{28}$ Ken-Ichiro Tsutsui, ${ }^{29}$ Tadashi Ogawa, ${ }^{10}$ Hidehiko Komatsu, ${ }^{10}$ Kowa Koida, ${ }^{30}$ Keisuke Toyama, ${ }^{3}$ Barry J. Richmond, ${ }^{31}$ and ${ }^{-S h i g e r u ~ S h i n o m o t o ~}{ }^{1}$

${ }^{1}$ Graduate School of Science, Kyoto University, Kyoto 606-8502, Japan, ${ }^{2}$ RIKEN Brain Science Institute, Saitama 351-0198, Japan, ${ }^{3}$ ATR Neural Information Analysis Laboratories, Kyoto 619-0288, Japan, ${ }^{4}$ Department of Human and Computer Intelligence, Ritsumeikan University, Shiga 525-8577, Japan, ${ }^{5}$ Brain Science Institute, Tamagawa University, Tokyo 194-8610, Japan, ${ }^{6}$ Graduate School of Medicine and ${ }^{7}$ Kokoro Research Center, Kyoto University, Kyoto 606-8501, Japan, ${ }^{8}$ Graduate School of Brain Science, Doshisha University, Kyoto 610-0394, Japan, ${ }^{9}$ Department of Developmental Physiology and ${ }^{10}$ Division of Sensory and Cognitive Information, National Institute for Physiological Sciences, Aichi 444-8585, Japan, ${ }^{11}$ Graduate School of Frontier Biosciences, Osaka University, Osaka 565-0871, Japan, ${ }^{12}$ Center for Synaptic Brain Dysfunctions, Institute for Basic Science, Daejeon 305-701, Korea, ${ }^{13}$ Kyungpook National University School of Medicine, Daegu 700-422, Korea, ${ }^{14}$ Department of Biological Sciences, Korea Advanced Institute of Science and Technology, Daejeon 305-701, Korea, ${ }^{15}$ Biomedical Neuroscience Institute, Universidad de Chile, Santiago 8380453, Chile, ${ }^{16}$ Department of Organismal Biology and Anatomy and ${ }^{17}$ Committee of Computational Neuroscience, University of Chicago, Chicago, Illinois 60637, ${ }^{18}$ Faculty of Dentistry, University of Toronto, Toronto M5G 1G6, Canada, ${ }^{19}$ Institut de Neurosciences de la Timone, CNRS-AMU, Marseille 13005, France, ${ }^{20}$ Institute of Neuroscience and Medicine (INM-6) \& Institute for Advanced Simulation (IAS-6) \& JARA Brain Institute I, Jülich 52425, Germany, ${ }^{21}$ Theoretical Systems Neurobiology, RWTH Aachen University, Aachen 52056, Germany, ${ }^{22}$ Graduate School of Medicine and Pharmaceutical Sciences, University of Toyama, Toyama 930-0194, Japan, ${ }^{23}$ School of Health Science, Sapporo Medical University, Sapporo 060-8556, Japan, ${ }^{24}$ Department of Physiology, School of Medicine, Tohoku University, Sendai 980-8575, Japan, ${ }^{25}$ Center for Information and Neural Networks, Osaka University and National Institute of Information and Communications Technology, Osaka 565-0871, Japan, ${ }^{26}$ Department of Physiology, School of Medicine, Hokkaido University, Sapporo 060-8638, Japan, ${ }^{27}$ Department of Physiology, Hirosaki University Graduate School of Medicine, Hirosaki 036-8562, Japan, ${ }^{28} \mathrm{Graduate}$ School of Medical and Dental Sciences, Tokyo Medical and Dental University, Tokyo 113-8549, Japan, ${ }^{29}$ Laboratory of Systems Neuroscience, Graduate School of Life Sciences, Tohoku University, Sendai 980-8577, Japan, ${ }^{30}$ Electronics-Inspired Interdisciplinary Research Institute, Toyohashi University of Technology, Aichi 441-8580, Japan, and ${ }^{31}$ Laboratory of Neuropsychology, National Institute of Mental Health, National Institutes of Health, Bethesda, Maryland 20892
\end{abstract}

The architectonic subdivisions of the brain are believed to be functional modules, each processing parts of global functions. Previously, we showed that neurons in different regions operate in different firing regimes in monkeys. It is possible that firing regimes reflect differences in underlying information processing, and consequently the firing regimes in homologous regions across animal species might be similar. We analyzed neuronal spike trains recorded from behaving mice, rats, cats, and monkeys. The firing regularity differed systematically, with differences across regions in one species being greater than the differences in similar areas across species. Neuronal firing was consistently most regular in motor areas, nearly random in visual and prefrontal/medial prefrontal cortical areas, and bursting in the hippocampus in all animals examined. This suggests that firing regularity (or irregularity) plays a key role in neural computation in each functional subdivision, depending on the types of information being carried.

Key words: firing irregularity/regularity; interspecies similarity; neuronal firing pattern; neuronal firing regime

Significance Statement

By analyzing neuronal spike trains recorded from mice, rats, cats, and monkeys, we found that different brain regions have intrinsically different firing regimes that are more similar in homologous areas across species than across areas in one species. Because different regions in the brain are specialized for different functions, the present finding suggests that the different activity regimes of neurons are important for supporting different functions, so that appropriate neuronal codes can be used for different modalities. 


\section{Introduction}

Two principles underlie systems neuroscience: first, that neurons are the principal carriers of information (Ramón y Cajal, 1899; Bullock et al., 2005; DeFelipe, 2010), and second, that the neurons in different architectonically defined brain regions are specialized both by their morphology and by the intrinsic circuitry so that they process information differently than other brain regions (Brodmann, 1909; Elston, 2003; Toga et al., 2006; Zilles and Amunts, 2010). Because different types of organization exhibit different dynamics, these two principles may be combined so that neuronal firing patterns are dependent specifically on different types of circuit organization and related to the functions for which a given brain region is specialized.

If it is true that the specific firing patterns are important for particular neuronal computations, the firing patterns of neurons in different brain regions ought to be different. Previous studies support this supposition; there are statistical features of neuronal firing that vary considerably across cortical regions of monkeys (Shinomoto et al., 2003, 2009; Maimon and Assad, 2009; Murray et al., 2014). If we postulate that these intrinsic features of neuronal firing evolved to optimize a particular type of local neuronal information processing, we might find that the firing patterns in homologous brain regions in different animal species (Brodmann, 1909; Northcutt and Kaas, 1995) will be more similar than firing patterns seen from one region to another within a species.

In this report, we examined neuronal firing from sets of homologous brain areas of behaving mice, rats, cats, and monkeys (macaques) using $>2000$ spike trains. Ideally, it would be best to perform these measurements using tasks that are similar across species and when recording in a variety of brain regions. However, such data do not seem to exist. In neurophysiology experiments, behavior is generally shaped according to the hypothesized specialization of the tissue under study and the interests of the investigators. In the data analyzed here, the neuronal activity was recorded while the individual subjects were awake and actively engaged in behavioral tasks. We characterized these spike trains using the firing rate, firing regularity, and serial correlation of interspike intervals (ISIs).

Received Jan. 22, 2016; revised April 10, 2016; accepted April 12, 2016.

Author contributions: Y.M., B.J.R., and S.S. designed research; Y.T., R.K., A.S., Y. Sakai, Y.I., S. Fujisawa, K.-i.S., D.H., T.F., T. Kaneko, S.T., T.N., S.I., Y. Sakurai, T. Kitsukawa, J.W.L., H.L., M.W.J., C.B., P.E.M., K. Takahashi, F.I.A.-M., C.F.R., B.J.S., N.G.H., T.B., A.R., P.C., S.G., H.N., S.I.-T., S. Funahashi, K.S., H.M., Y.Y., H.T., I.F., N.I., K. Kawano, S.K., K.F., K. Kurata, M.T., K.-I.T., T. Ogawa, H.K., K. Koida, and K. Toyama performed research; Y.M., T. Onaga, H.S., and T.S. analyzed data; B.J.R. and S.S. wrote the paper.

The authors declare no competing financial interests.

This work was supported by Grants-in-Aid for Scientific Research from Ministry of Education, Culture, Sports, Science and Technology of Japan (Contracts 25115718 and 26280007 to S.S.; Contracts 24300148 and 25560435 to S.T.); the Japan Science and Technology Agency (JST; S.S.); the JST Strategic International Research Cooperative Program (Japan-Germany) (H.T.); CREST (S.S.); National Institute of Information and Communications Technology Contract "Development of network dynamics modeling methods for human brain data simulation systems" (T.S.); Japan Society for the Promotion of Science KAKENHI Grant 26330288 (Y.T.); Strategic Information and Communications R\&D Promotion Programme (SCOPE) from Ministry of Internal Affairs and Communications (Contract 152107008; S.T.); the Research Center Program of the Institute for Basic Science, Korea (Grant IBS-R002-G1; M.W.J.); FONDECYT Grant 1981184 (P.M., C.B.); ICM Grant P09-015F (P.M., C.B.); L'Agence nationale de la recherche-GRASP (France) (T.B., A.R.); the RIKEN-CNRS Collaborative Research Agreement (T.B., A.R.); the German-Japanese Computational Neuroscience Project (BMBF Grant 01GQ1114; S.G.); the Human Brain Project (Grant 604102; S.G.); Helmholtz Portfolio Theme "Supercomputing and Modeling for the Human Brain" (S.G.); Klinische Forschergruppe KF0219 (TP12, Deutsche Forschungsgemeinschaft Grant GR 1753/3-1; S.G.), the Naito Foundation Subsidy for Female Researchers after Maternity Leave (Y.Y.), and the Intramural Research Program of the U.S. National Institute of Mental Health (B.J.R.). We thank Kai Shinomoto for making pictures of animals for Figure 4. We thank Taro Toyoizumi, Okito Yamashita, and anonymous reviewers for thoughtful and constructive comments on this manuscript.

Correspondence should be addressed to Shigeru Shinomoto, Graduate School of Science, Kyoto University, Sakyo-ku, Kyoto 606-8502, Japan. E-mail: shinomoto@scphys.kyoto-u.ac.jp.

DOI:10.1523/JNEUROSCI.0230-16.2016

Copyright $\odot 2016$ the authors $\quad 0270-6474 / 16 / 365737-12 \$ 15.00 / 0$
Despite the differences in behavior, the firing regularity (defined as the variability of ISIs) differed systematically across different cortical regions, and was related across species.

\section{Materials and Methods}

\section{Neuronal spike data}

Spike trains were recorded from motor, visual, and prefrontal cortices, as well as hippocampus from mice, rats, cats, and monkeys of either sex. To see the degree to which firing characteristics depend on the recording methods and behavioral tasks, for each brain region, we grouped spike trains according to the experimental laboratories that obtained them. This provided 36 data sets: cortical motor areas of mice ( 1 data set), rats ( 2 data sets), and monkeys (11 data sets); visual areas of cats ( 1 data set) and monkeys ( 9 data sets); sensory (barrel) cortex of rats (1 data set); medial prefrontal cortex (mPFC) of rats (2 data sets) and monkeys (2 data sets); and hippocampus of mice (1 data set), rats (4 data sets), and monkeys (2 data sets; Table 1). For the data in which spike sorting was involved, we accepted the criteria for isolating spikes of a single neuron that have been used in respective experimental groups. We used the initial segment containing 2001 consecutive spikes, i.e., 2000 ISIs, without regard to task trial periods or intertrial intervals. For some monkey data in which recording had been suspended during intertrial intervals, we concatenated no more than 20 spike trains obtained in successive trials by superimposing the last spike in the preceding trial on the first spike in the succeeding trial. Spike trains that contained fewer than 2001 spikes or those with mean firing rates $<2$ spikes/s were discarded. Our requirement for spike trains to contain $>2000$ spikes imposed a priority for neurons of high firing rate. Ninety-one percent of spike trains exceeded the firing rate threshold. This yielded 2259 spike trains for firing-pattern analysis.

All procedures for animal care and experimentation were in accordance with the guidelines of the National Institutes of Health and approved by the animal experiment committees at the institutions where the experiments were performed.

\section{Analysis of firing patterns}

\section{Characterization of firing patterns}

We estimated the firing rate, firing regularity, and ISI correlation for each spike train to search for firing characteristics that can be related to the functional regions (Fig. 1). Each spike train consisting of 2000 ISIs was divided into $m=100$ segments of $n=20$ ISIs, and each measurement was made for each segment. The results from these 100 segments were averaged for each spike train. The firing rate and firing regularity were quantified by fitting the gamma distribution (Kuffler et al., 1957; Stein, 1965; Reich et al., 1998; Brown et al., 2002; Shimokawa and Shinomoto, 2009):

$$
g_{\lambda, \kappa}(I)=(\lambda \kappa)^{\kappa} I^{\kappa-1} e^{-\lambda \kappa I} / \Gamma(\kappa),
$$

where $I$ is the duration of a given ISI, $\kappa$ and $\lambda$ are the shape and scale factors, respectively, and $\Gamma(x)$ is the gamma function.

Firing rate. The maximum likelihood estimation of the scale factor $\lambda$ of the gamma distribution gives the firing rate as follows:

$$
\lambda=\frac{n}{\sum_{i=1}^{n} I_{i}},
$$

where $I_{i}$ is the duration of the $i$ th ISI. We indicate the firing activity in terms of the log firing rate averaged over $m(=100)$ segments, as follows:

$$
\langle\log \lambda\rangle=\frac{1}{m} \sum_{j=1}^{m} \log \lambda_{j}
$$

where $\lambda_{j}$ represents the firing rate in the $j$ th segment. We take the logarithm of the firing rate $\lambda$ as well as the shape parameter $\kappa$, because the information distance between different gamma distributions scales approximately with $\log \lambda$ and $\log \kappa$ (Miura et al., 2006). 
Table 1. List of the animals, cortical areas, number of neurons, firing metrics, and principal researchers

\begin{tabular}{|c|c|c|c|c|c|c|c|c|c|c|c|c|c|}
\hline \multirow[b]{2}{*}{ No. } & \multirow[b]{2}{*}{ Animal } & \multirow{2}{*}{$\begin{array}{l}\text { Functional } \\
\text { category }\end{array}$} & \multirow{2}{*}{$\begin{array}{l}\text { Cortical } \\
\text { area }\end{array}$} & \multirow{2}{*}{$\begin{array}{l}\text { No. of } \\
\text { neurons }\end{array}$} & \multicolumn{8}{|c|}{ Firing metrics (left, mean; right, dispersion) } & \multirow{2}{*}{$\begin{array}{l}\text { Principal } \\
\text { researcher }\end{array}$} \\
\hline & & & & & $\log \kappa$ & & $\log \lambda$ & & $\rho$ & & $L v$ & & \\
\hline 1 & Rat & Motor & M1 & 30 & 0.72 & 0.59 & 2.19 & 0.73 & 0.08 & 0.06 & 0.58 & 0.27 & Furuta \\
\hline 2 & Rat & Motor & $\mathrm{M} 1 / \mathrm{CFA}$ & 114 & 0.47 & 0.53 & 1.52 & 0.61 & 0.04 & 0.07 & 0.71 & 0.25 & Isomura \\
\hline 3 & Rat & $\mathrm{PF}$ & $\mathrm{mPFC}$ & 23 & 0.03 & 0.28 & 1.48 & 0.46 & 0.01 & 0.06 & 0.97 & 0.19 & Sakurai \\
\hline 4 & Rat & PF & $\mathrm{mPFC}$ & 40 & -0.07 & 0.31 & 1.71 & 0.78 & 0.08 & 0.05 & 0.95 & 0.19 & Fujisawa \\
\hline 5 & Rat & Sensory & S1/barrel cortex & 32 & -0.13 & 0.34 & 2.07 & 0.53 & 0.09 & 0.08 & 0.98 & 0.24 & Furuta \\
\hline 6 & Rat & Hippocampus & Subiculum & 81 & -0.20 & 0.46 & 1.77 & 0.57 & 0.07 & 0.09 & 1.03 & 0.24 & Jung \\
\hline 7 & Rat & Hippocampus & CA1 & 28 & -0.24 & 0.45 & 1.93 & 0.83 & -0.01 & 0.08 & 1.15 & 0.27 & Fujisawa \\
\hline 8 & Rat & Hippocampus & CA1 & 18 & -0.43 & 0.53 & 1.38 & 0.77 & -0.09 & 0.12 & 1.31 & 0.38 & Takahashi \\
\hline 9 & Rat & Hippocampus & CA1 & 66 & -0.47 & 0.50 & 1.72 & 0.67 & -0.02 & 0.11 & 1.22 & 0.33 & Jung \\
\hline 10 & Mouse & Motor & Motor & 26 & 0.22 & 0.36 & 2.09 & 0.52 & 0.04 & 0.06 & 0.81 & 0.17 & Kitsukawa \\
\hline 11 & Mouse & Hippocampus & CA1 & 32 & -0.40 & 0.56 & 1.82 & 0.60 & -0.09 & 0.15 & 1.27 & 0.40 & Jung \\
\hline 12 & Cat & Visual & V1 & 26 & -0.14 & 0.27 & 3.01 & 0.56 & -0.02 & 0.09 & 1.03 & 0.24 & Maldonado \\
\hline 13 & Monkey & Motor & M1 & 29 & 1.22 & 1.08 & 3.03 & 0.60 & 0.18 & 0.12 & 0.40 & 0.25 & Kurata \\
\hline 14 & Monkey & Motor & SMA & 83 & 1.20 & 0.68 & 3.03 & 0.49 & 0.06 & 0.15 & 0.43 & 0.21 & Kurata \\
\hline 15 & Monkey & Motor & PMv & 30 & 1.11 & 0.71 & 3.27 & 0.55 & 0.00 & 0.19 & 0.49 & 0.21 & Kurata \\
\hline 16 & Monkey & Motor & PMd & 192 & 1.00 & 0.75 & 3.00 & 0.55 & 0.09 & 0.17 & 0.51 & 0.29 & Kurata \\
\hline 17 & Monkey & Motor & SEF & 103 & 0.67 & 0.50 & 2.72 & 0.41 & 0.13 & 0.12 & 0.55 & 0.24 & Fukushima \\
\hline 18 & Monkey & Motor & CMAr & 27 & 0.65 & 0.44 & 2.73 & 0.53 & 0.05 & 0.07 & 0.63 & 0.23 & Tanji \\
\hline 19 & Monkey & Motor & SMA & 27 & 0.57 & 0.48 & 2.92 & 0.58 & 0.06 & 0.10 & 0.66 & 0.24 & Tanji \\
\hline 20 & Monkey & Motor & M1 & 40 & 0.50 & 0.36 & 2.93 & 0.62 & 0.04 & 0.11 & 0.69 & 0.19 & Hatsopoulos \\
\hline 21 & Monkey & Motor & presMA & 125 & 0.47 & 0.42 & 2.59 & 0.57 & 0.08 & 0.09 & 0.68 & 0.24 & Tanji \\
\hline 22 & Monkey & Motor & FEF & 45 & 0.46 & 0.33 & 3.03 & 0.40 & 0.15 & 0.11 & 0.60 & 0.16 & Fukushima \\
\hline 23 & Monkey & Visual & MST & 77 & 0.36 & 0.43 & 2.89 & 0.49 & 0.11 & 0.11 & 0.71 & 0.25 & Kawano \\
\hline 24 & Monkey & Visual & V1 & 35 & 0.35 & 0.38 & 3.55 & 0.42 & 0.11 & 0.08 & 0.67 & 0.22 & Komatsu \\
\hline 25 & Monkey & Motor & M1/PMd & 142 & 0.32 & 0.46 & 2.29 & 0.70 & 0.11 & 0.11 & 0.73 & 0.23 & Riehle \\
\hline 26 & Monkey & $\mathrm{PF}$ & $\mathrm{PF}$ & 22 & 0.30 & 0.14 & 3.30 & 0.62 & 0.03 & 0.08 & 0.79 & 0.11 & Tanji \\
\hline 27 & Monkey & Visual & TE & 97 & 0.15 & 0.41 & 2.05 & 0.75 & 0.03 & 0.08 & 0.87 & 0.24 & Fujita \\
\hline 28 & Monkey & Visual & TE & 103 & 0.15 & 0.47 & 2.49 & 0.65 & 0.16 & 0.13 & 0.73 & 0.28 & Komatsu \\
\hline 29 & Monkey & Visual & CIP & 158 & 0.10 & 0.43 & 2.85 & 0.55 & 0.03 & 0.11 & 0.92 & 0.27 & Tsutsui \\
\hline 30 & Monkey & Visual & MST & 100 & 0.10 & 0.38 & 2.81 & 0.59 & 0.07 & 0.11 & 0.85 & 0.28 & Fukushima \\
\hline 31 & Monkey & Hippocampus & Hippocampus & 37 & 0.06 & 0.53 & 2.27 & 0.76 & 0.09 & 0.10 & 0.87 & 0.27 & Nishijo \\
\hline 32 & Monkey & Hippocampus & Parahippocampus & 23 & 0.02 & 0.50 & 2.07 & 0.70 & 0.12 & 0.12 & 0.84 & 0.26 & Nishijo \\
\hline 33 & Monkey & Visual & MT & 58 & 0.02 & 0.32 & 3.42 & 0.54 & 0.07 & 0.09 & 0.86 & 0.19 & Kawano \\
\hline 34 & Monkey & Visual & STS & 56 & -0.09 & 0.49 & 1.47 & 0.55 & 0.00 & 0.09 & 1.08 & 0.35 & Tamura \\
\hline 35 & Monkey & PF & PF & 131 & -0.11 & 0.29 & 2.41 & 0.44 & 0.05 & 0.07 & 1.04 & 0.17 & Funahashi \\
\hline 36 & Monkey & Visual & V4 & 35 & -0.19 & 0.35 & 2.56 & 0.81 & 0.08 & 0.13 & 0.94 & 0.29 & Komatsu \\
\hline
\end{tabular}

PMv, ventral premotor cortex; PMd, dorsal premotor cortex; SEF, supplementary eye field; CMAr, rostral cingulate motor area; FEF, frontal eye fields; MST, medial superior temporal area; TE, visual area TE; CIP, caudal intraparietal area; STS, superior temporal sulcus. Detailed information is available at http://www.ton.scphys.kyoto-u.ac.jp/ shino/brainmap/.

Firing regularity. The shape factor $\kappa$ of the gamma distribution represents the firing regularity. This is estimated by maximizing the likelihood, which is achieved by solving the following equation:

$$
\log \kappa-\psi(\kappa)=\log \left(\frac{1}{n} \sum_{i=1}^{n} I_{i}\right)-\frac{1}{n} \sum_{i=1}^{n} \log I_{i},
$$

where $\psi(x)$ is the digamma function (Cox and Lewis, 1966). We represent the regularity of a given spike train by averaging the logarithm of the shape factor over $m$ segments:

$$
\langle\log \kappa\rangle=\frac{1}{m} \sum_{j=1}^{m} \log \kappa_{j} .
$$

Firing regularity $\log \kappa$ is expected to take a value of 0 (i.e., $\kappa=1$ ) for a Poisson spike train and becomes positive or negative if firings are more regular $(\kappa>1)$ or bursting $(\kappa<1)$, respectively (Fig. $1 B, C)$.

ISI correlation. We estimated the correlation of consecutive ISIs using Spearman's rank-order correlation of order one (Kuffler et al., 1957; Farkhooi et al., 2009; Fig. 1B). For each segment of a spike train or a sequence of ISIs $\left\{I_{1}, I_{2}, \ldots, I_{n}\right\}$, we indicated their rank order as $\left\{r_{1}, r_{2}, \ldots, r_{n}\right\}$, where $r_{i}$ denotes the rank of the $i$ th ISI, $I_{i}$, in ascending order. When there were sets of identical ISIs, they were each assigned the average rank. Spearman's rankorder correlation of order one is defined as follows:

$$
\rho=\frac{n}{n-1} \frac{\sum_{k=1}^{n-1}\left(r_{k}-\bar{r}\right)\left(r_{k+1}-\bar{r}\right)}{\sum_{k=1}^{n}\left(r_{k}-\bar{r}\right)},
$$

where $\bar{r}$ is the average of ranks $[=(n+1) / 2]$. By averaging the rank order over $m(=100)$ segments, we represented the degree of renewality of a given spike train of 2000 ISIs:

$$
\langle\rho\rangle=\frac{1}{m} \sum_{j=1}^{m} \rho_{j}
$$

Here we used rank-order correlation instead of raw ISI correlation to minimize the bias in the estimation, because the raw ISI correlation is sensitively dependent on the shape of the ISI distribution, and, in particular, it tends to give a bias for an asymmetric distribution, even if ISIs were derived independently.

\section{Comparison between data sets}

To compare firing patterns of sets of spike trains recorded from a particular cortical area by a particular laboratory, the mean and dispersion (as represented by the SD among spike trains in a given data set) of the firing characteristics were estimated for each set of spike trains collected by that laboratory (Fig. 2). The possible range of fluctuations in the mean and dispersion of firing characteristics due to sampling of neurons was estimated by a nonparametric bootstrap procedure as follows: (i) Draw 10 spike trains randomly from a data set (duplicated drawing of the same neuron is allowed), and compute the mean and dispersion of three metrics $\log \lambda, \log \kappa$, and $\rho$. (ii) Repeat process (i) 100 times to compute the average and covariance of mean and dispersion. (iii) Fit a twodimensional Gaussian distribution to the 100 points obtained from process (ii) to represent the fluctuations of mean and dispersion of a metric. 


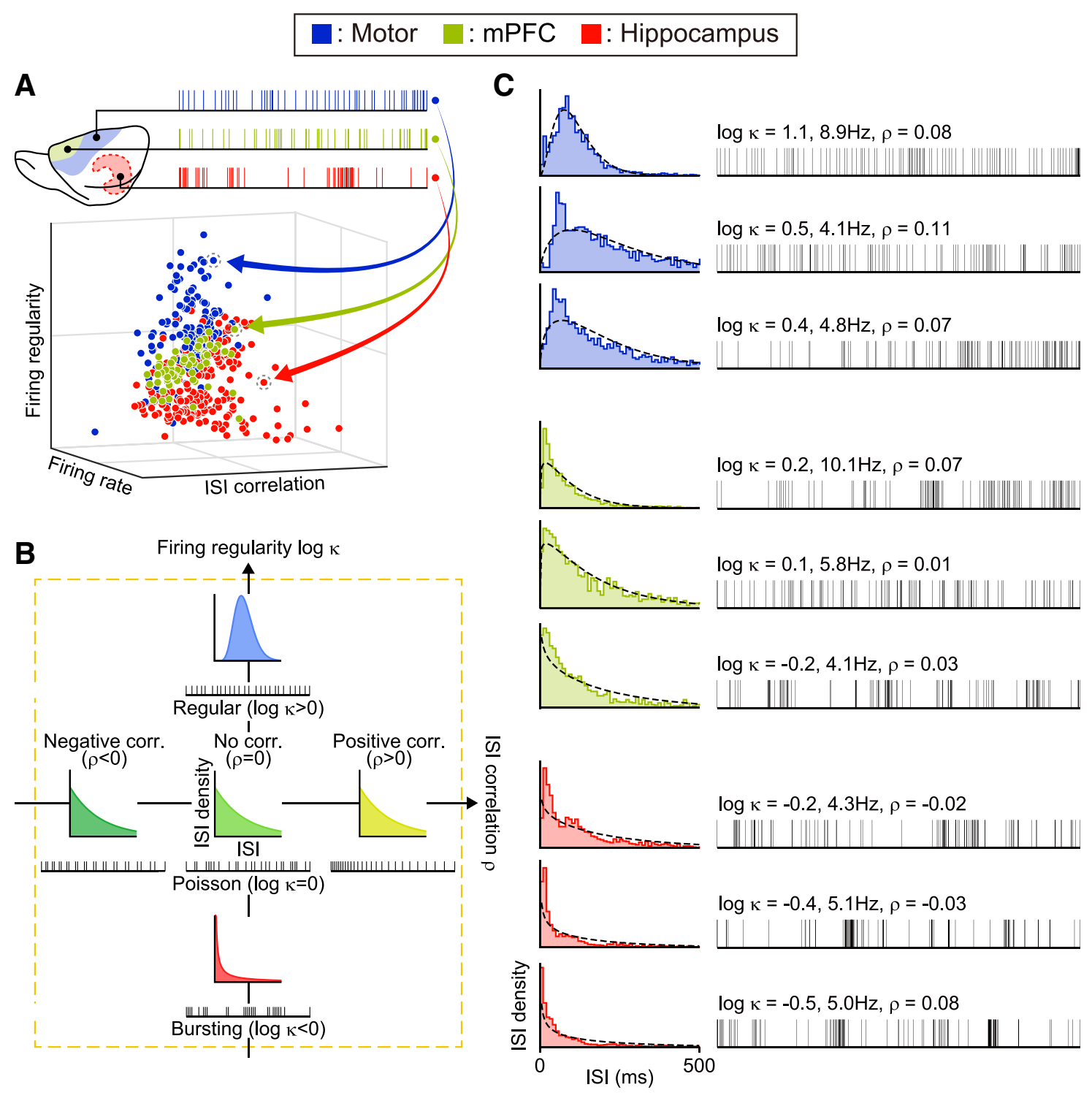

Figure 1. Characterizing neuronal spike trains. $A$, Mapping spike trains into pseudo-3D plots. Neuronal spike trains recorded from various functional areas are plotted with axes of firing rate, regularity, and ISI correlation. $B$, Firing regularity versus $I S I$ correlation. Firing regularity is defined as the logarithm of the shape factor $\kappa$ of the gamma distribution fitted to the $I S I$. A spike train is considered Poisson random if its ISIs are exponentially distributed $(\kappa=1$ or $\log \kappa=0)$, whereas it is considered regular if $\log \kappa>0$ or bursting if $\log \kappa<0$. The Spearman's rank-order correlation computed for sequentially paired ISIs indicates whether consecutive ISIs are positively correlated $(\rho>0)$ or negatively correlated $(\rho<0)$. C, Spike trains sampled from rat motor cortex, medial prefrontal cortex, and hippocampus with their corresponding ISI histograms. The dotted lines in ISI histograms show the best fit gamma distributions with the estimated values of $\kappa$ and $\lambda$. Raster plots show the first 101 spikes, or 100 ISIs.
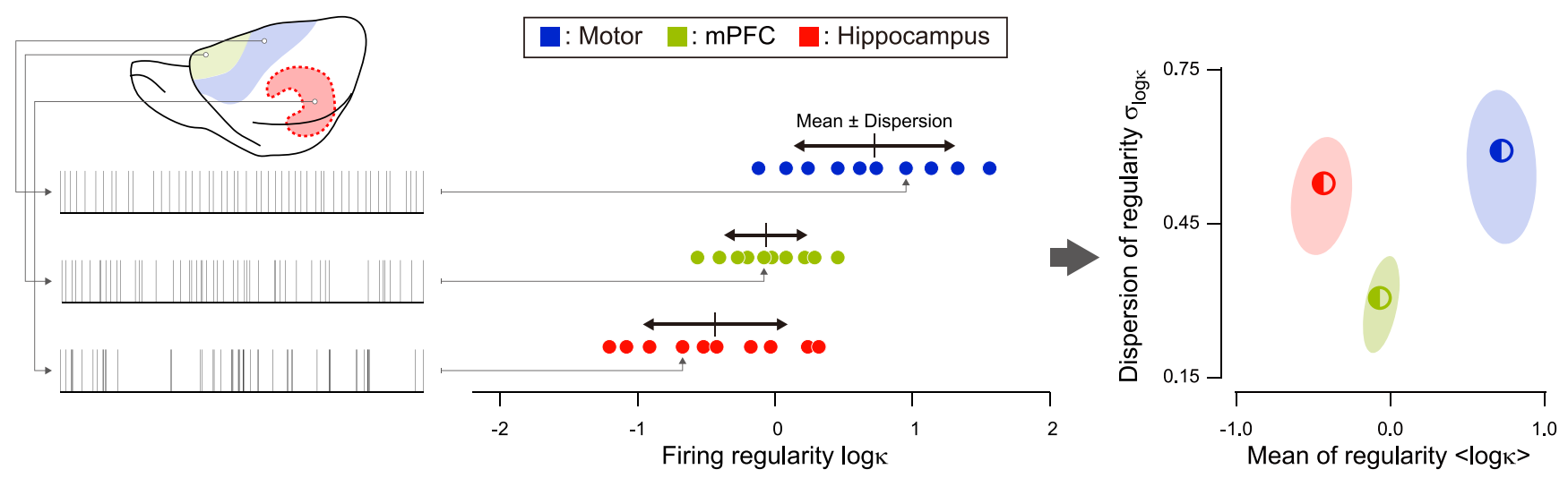

Figure 2. The mean and dispersion of firing characteristics. The distribution of firing characteristics of a given data set is represented by the mean and dispersion (defined as the SD of a sampled population). The ellipses represent the typical statistical fluctuation due to random sampling of neurons ( $75 \%$ confidence regions) estimated by the nonparametric bootstrap. 


\section{Hierarchical clustering}

To compare the degree to which a specific firing characteristic was correlated with the region of brain areas, we performed Ward's method of hierarchical clustering of the best fitting two-dimensional Gaussian distributions for the mean and dispersion of metrics obtained from the bootstrap procedure described above. We defined the distance between two distributions $P(x)$ and $Q(x)$ to be the Hellinger distance (Bishop, 2006), whose square is given by the following:

$$
H^{2}(P, Q)=\frac{1}{2} \int(\sqrt{P(x)}-\sqrt{Q(x)})^{2} d x .
$$

The Hellinger distance is zero when two distributions are identical, and unity for disjoint distributions.

Local variation of ISIs

Some of the authors analyzed monkeys' neuronal spike trains using an index of local variation of ISIs, $L v$ (Shinomoto et al., 2003), given as

$$
L v=\frac{3}{n-1} \sum_{i=1}^{n-1}\left(\frac{I_{i}-I_{i+1}}{I_{i}+I_{i+1}}\right)^{2},
$$

or its variant $L v R$ (Shinomoto et al., 2009). However, $L v$ may be interpreted as either the firing irregularity or the correlation between consecutive ISIs. This can be seen by expanding the summand as follows:

$$
\left(\frac{I_{i}-I_{i+1}}{I_{i}+I_{i+1}}\right)^{2}=1-\frac{4 I_{i} I_{i+1}}{\left(I_{i}+I_{i+1}\right)^{2}},
$$

where the second term on right-hand side is the rescaled correlation of consecutive ISIs.

\section{Results}

Regional specificity of firing characteristics

Using spike data obtained from rats and monkeys, we compared the firing characteristics across the first 1000 and last 1000 ISIs. The correlations of the firing rate log $\lambda$, firing regularity $\log \kappa$, and ISI correlation $\rho$ were strong, indicating that all firing characteristics were stable through the recordings of these individual neurons; $r=0.81,0.95$, and 0.83 , for rat data (Pearson correlation, $N=400, p<10^{-4}$ for all data), and $r=0.94,0.95$, and 0.86 for monkey data (Pearson correlation, $N=$ 1775, $p<10^{-4}$ for all data).

Figure 3, $A$ and $C$, presents the distributions for the data sets, with axes representing the mean and dispersion of firing rate, regularity, and ISI correlation. Here, the dispersion of firing characteristics is represented by the SD of sampled data (see Materials and Methods; Fig. 2). The ellipses represent typical fluctuations (75\% confidence regions) in the mean

\section{Rat $\quad$ : Motor : mPFC $\quad$ : Hippocampus}

\section{A Firing rate $\log \lambda \quad$ Firing regularity $\log \kappa \quad$ ISI correlation $\rho$}
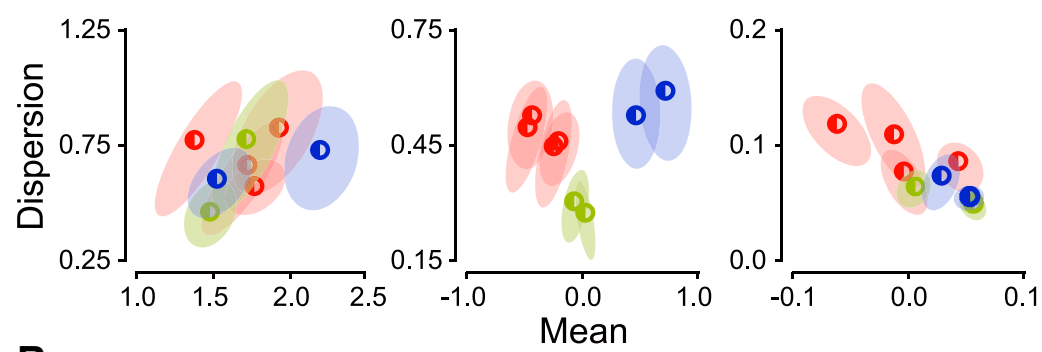

B
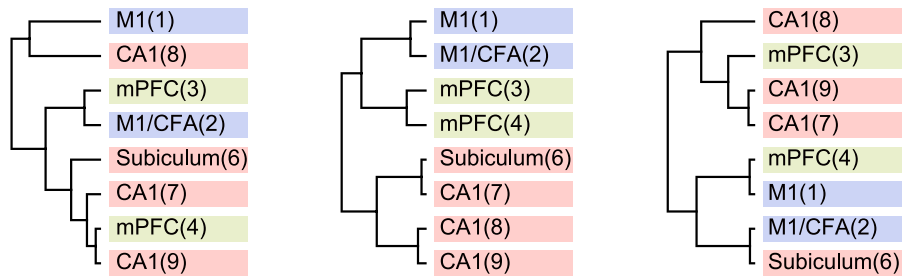

C Firing rate $\log \lambda \quad$ Firing regularity $\log \kappa \quad$ ISI correlation $\rho$
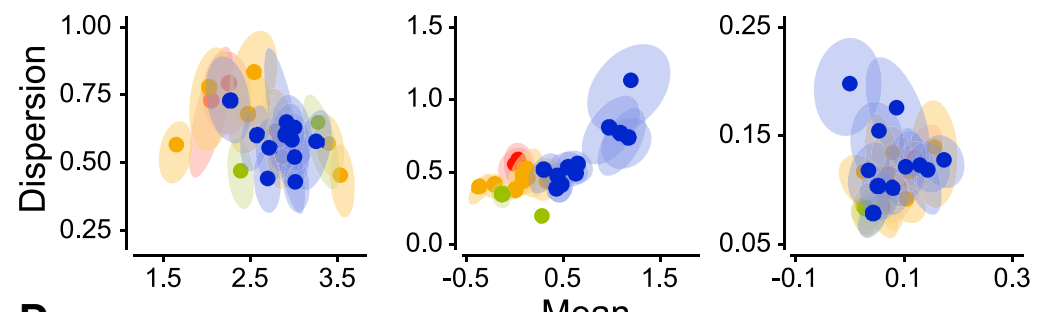

D
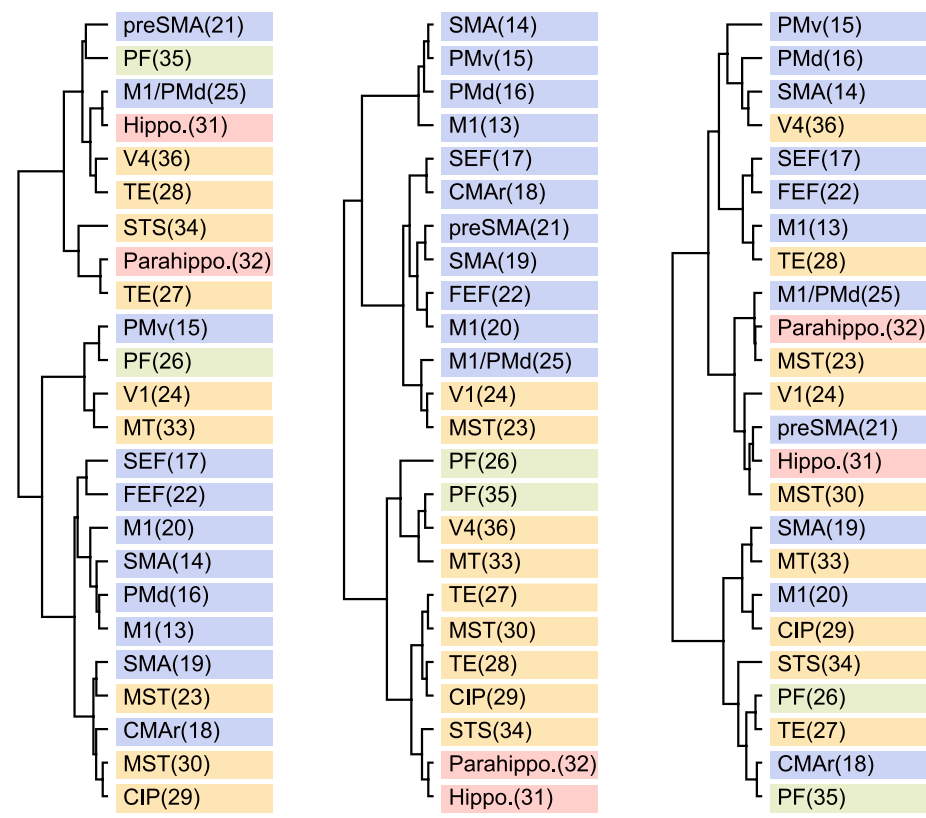

Figure 3. Regional specificity of three firing characteristics (rats andmonkeys).A,C,Distributions of the firing characteristics of different data sets. Each circle represents the mean and dispersion (as represented by the SD of the sampled population) of each firing metric for a neuronal population collected by an individual experimental group, and the surrounding ellipse represents the typical statistical fluctuation due to random sampling of 10 neurons (75\% confidence region). $\boldsymbol{B}, \boldsymbol{D}$, Hierarchical clustering of the data sets applied to the mean and dispersion of firing characteristics (see Materials and Methods). The numbers in the parentheses refer to the data sets in Table 1. 


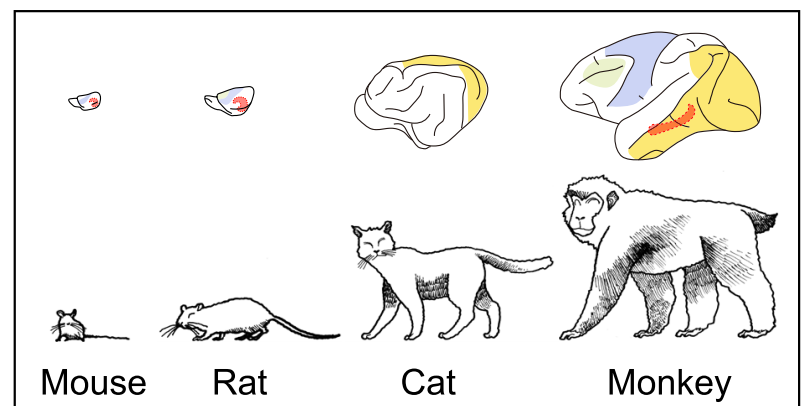

A

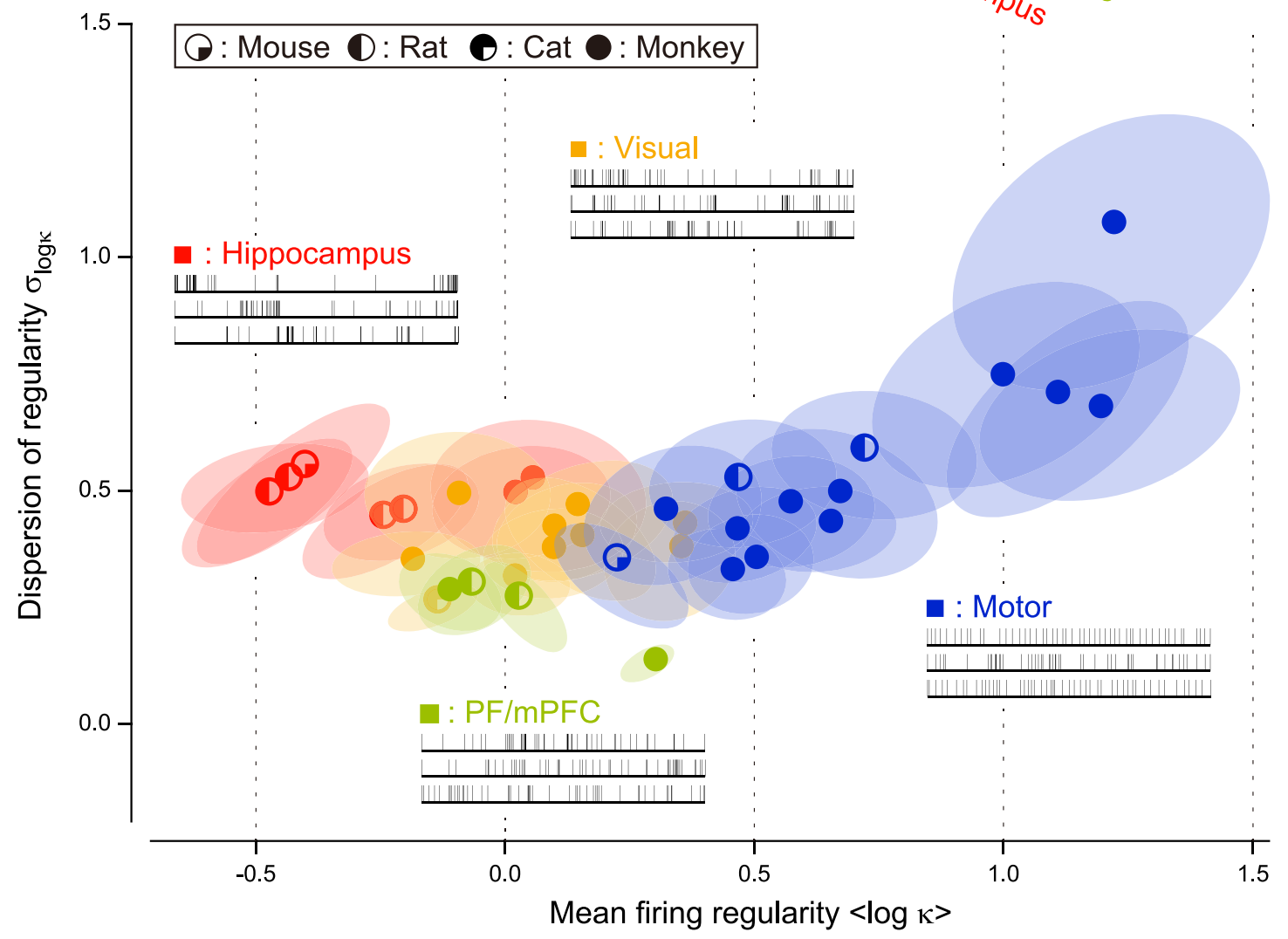

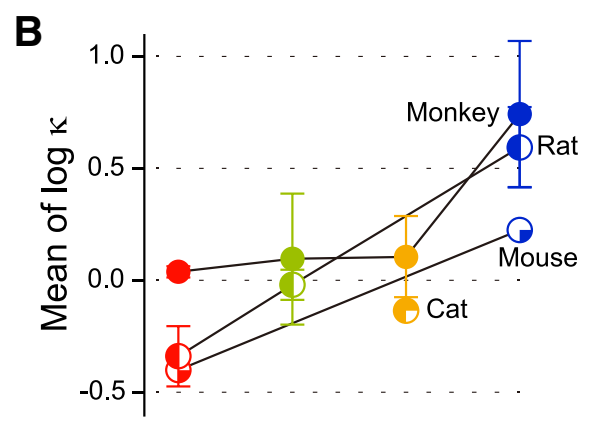

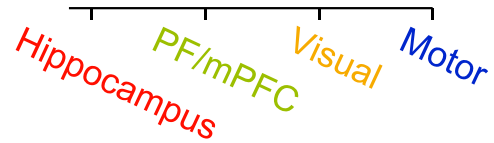

Figure 4. Distribution of firing regularity among various functional areas of mice, rats, cats, and monkeys. $A$, The mean and dispersion of firing regularity log $\kappa$. The quarter-filled, half-filled, three-quarterfilled, and fully filled circles represent average values of individual data sets of mice, rats, cats, and monkeys, respectively. The ellipses represent the range of typical deviation (75\% confidence regions) of respective data sets due to the finite sampling size of neurons. $\boldsymbol{B}$, The average firing regularity in four functional areas of different animals. The error bars indicate SDs.

and dispersion of metrics due to sampling; each range was obtained by nonparametric bootstrapping, by randomly sampling 10 spike trains from a given data set (see Materials and Methods). Although the firing characteristics might have depended on individual laboratories' recording methods as well as behavioral tasks, data sets from the same functional areas were better clustered in terms of the firing regularity $\log \kappa$ than in terms of the firing rate $\log \lambda$ or ISI correlation $\rho$. Figure $3, B$ and $D$, presents the results of the hierarchical clustering applied to the data points in panels $A$ and $C$ (Ward's method based on the Hellinger distance between distributions obtained from bootstrapping; see Materials and Methods), indicating the superior regional specificity of the firing regularity $\log \kappa$. The mean firing regularity was similar in prefrontal and visual cortices, but its dispersion (SD) was smaller in the prefrontal cortex than in visual cortices (Fig. $3 C)$. This implies that the prefrontal cortex does not have a vari- 

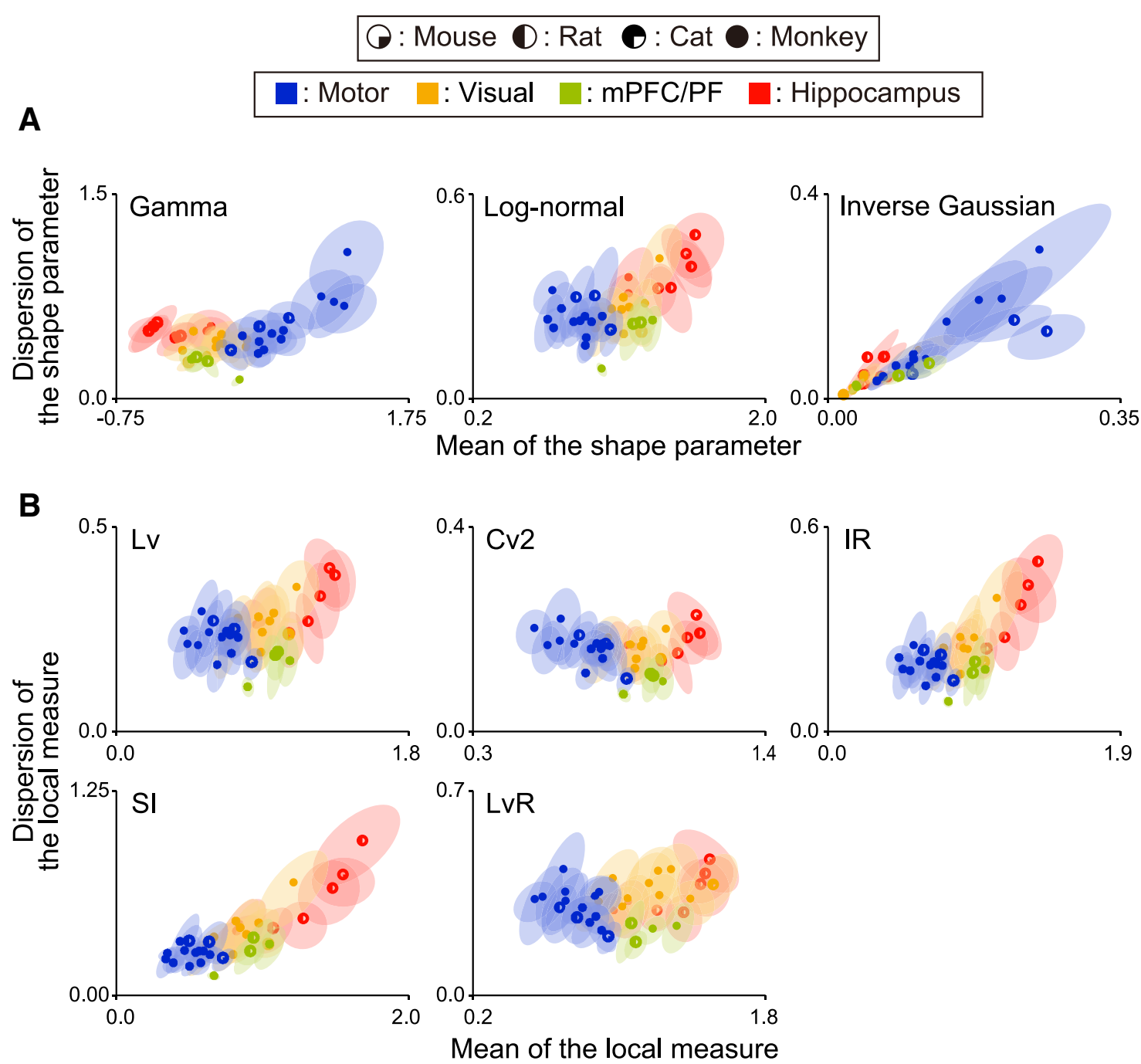

Figure 5. Distributions of firing regularity estimated by various firing metrics. A, Fitting ISI distribution with three kinds of families of distribution: the gamma distribution (left; Kuffler et al., 1957; Stein, 1965; Fig. 4A), the log-normal distribution (middle; Burns and Webb, 1976), and the inverse Gaussian distribution (right; Gerstein and Mandelbrot, 1964). B, Various local metrics of firing irregularity: Lv (top left; Shinomoto et al., 2003), Cv2 (top middle; Holt et al., 1996), IR (top right; Davies et al., 2006), SI (bottom left; Miura et al., 2006), and LvR (bottom right; Shinomoto et al., 2009). Differences in firing regularity among cortical areas can be seen consistently, regardless of the fitting functions or the choice of the local metric.

\section{Interspecies similarity of firing regularity across homologous regions}

Neuronal firing was regular in motor areas $(\log \kappa>0)$, nearly Poisson in visual and prefrontal/medial prefrontal cortical areas $(\log \kappa \sim 0)$, and bursting $(\log \kappa<0)$ in the hippocampus in all the animals examined (Fig. 4). The differentiation of functional areas was also observed when fitting with other families of distribution functions, or when using other metrics of firing irregularity (Fig. 5).

To compare the degree to which the firing regularity depends on brain regions and species, we computed the $F$ test statistic that measures the between-group variability relative to within-group variability and the proportion of variance explained that measures the sum of squares between groups relative to the sum of squares in total. The $F$ test statistic across the four brain region types turned out to be very large $\left(F_{(3,765)}=308.61\right)$, absolutely greater than the one across the four species $\left(F_{(3,93)}=68.32\right)$. The variance explained indicated consistent results: $\eta^{2}=0.30$ and 0.06 , respectively, for brain regions and species. Therefore, the firing regularity is better clustered in brain region types than in species.
We also compared other firing characteristics across brain regions and species. The firing rate exhibited a result opposite to the firing regularity; $F_{(3,686)}=106.64$ and $F_{(3,88)}=250.54$, and $\eta^{2}=0.11$ and 0.24 , respectively, for brain regions and species. This means that the firing rate was better clustered in species than in brain region types, as is observed in the distribution of firing rates (Fig. 6, Table 1). The ISI correlation is rather noncommittal to the factors, compared to the firing regularity and firing rate; $F_{(3,88)}=41.73$ and $F_{(3,761)}=24.61$, and $\eta^{2}=0.03$ and 0.05 , respectively, for brain regions and species.

\section{Temporal variation of firing characteristics}

So far, we have examined neuronal firing characteristics regardless of stimulus or behavioral conditions. Because neuronal firing may change according to these factors, it is important to grasp the extent to which the firing characteristics may vary depending on conditions. To this end, we analyzed spike trains recorded from both the presupplementary motor area (preSMA; data set 21) and PF (data set 26) while the same monkeys were performing the same task (Mita et al., 2009); the monkeys were required to hold down a key when a visual cue was given for $2 \mathrm{~s}$. 


\section{(1: Mouse : Rat $\mathbf{O}$ : Cat : Monkey}

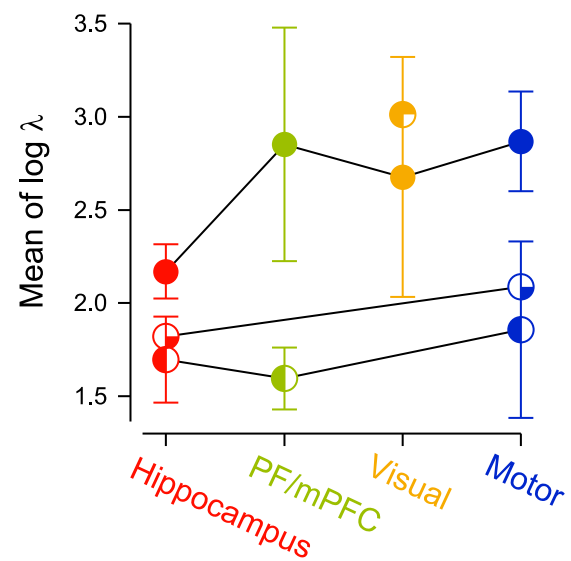

Figure 6. Interspecies comparison of the firing rate. The average firing rate is plotted for four functional areas of different animals. Error bars indicateSDs.

\section{preSMA : PF}

A Firing rate $\log \lambda \quad$ Firing regularity $\log \kappa \quad$ ISI correlation $\rho$
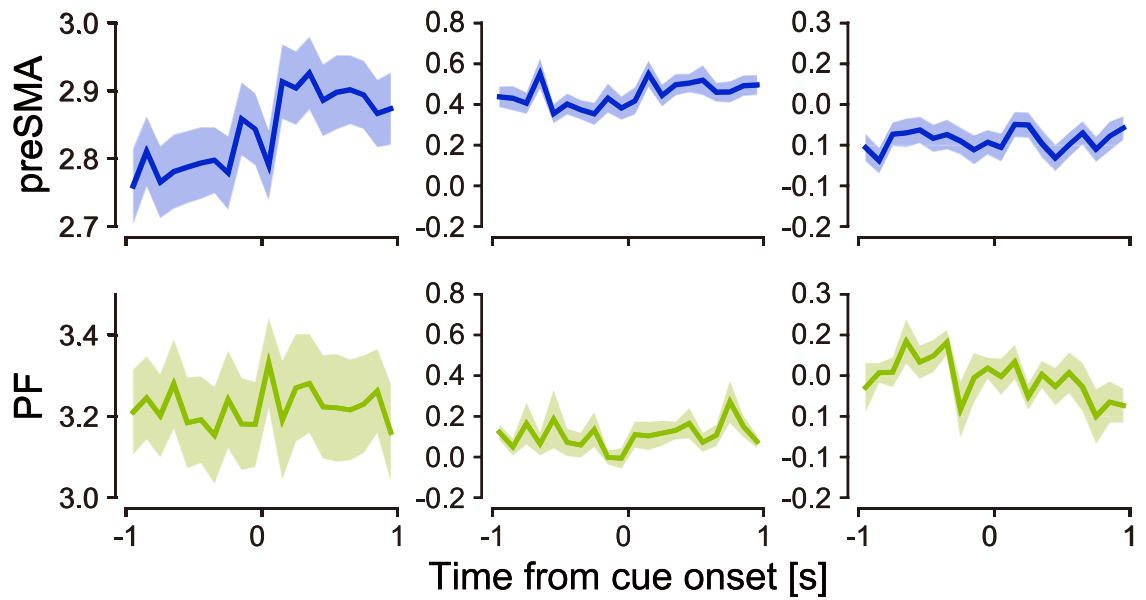

B Firing rate $\log \lambda$
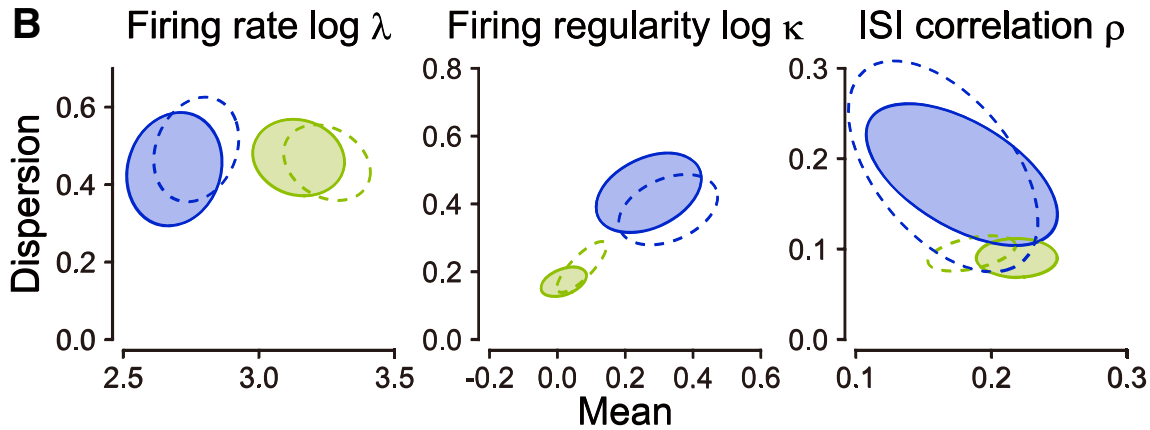

Figure 7. Temporal variation of firing characteristics. $A$, Population histograms of firing rates, firing regularity, and ISI correlation of neurons in preSMA and PF of monkeys aligned at cue onset. The shaded regions represent SEs. $B$, Distributions of the firing characteristics estimated before (solid ellipses representing 75\% confidence regions) and after (dashed ellipses) cue onset for neuronal populations.

Figure $7 \mathrm{~A}$ demonstrates the peristimulus histograms of average firing rate, firing regularity, and ISI correlation in these areas. In terms of the ensemble firing rates, both the preSMA and PF exhibited significant response to the cue stimulus (paired $t$ tests for spikes occurred in two intervals of $1000 \mathrm{~ms}$ before and after cue onset, $t_{(117)}=-2.84, p \sim 0.005$ and $t_{(21)}$ $=-2.86, p \sim 0.009)$. The intraneuronal differences in firing regularity caused by the stimulus were relatively small; we observed a certain change only in preSMA $\left(t_{(114)}=-2.68, p \sim\right.$ , but not in $\operatorname{PF}\left(t_{(21)}=-1.32, p \sim 0.2\right)$. The increase of likely to be due at least partially to the influence of the refractory period (Werner and Mountcastle, 1963; Softky and Koch, 993; Holt et al., 1996). There was a small change in ISI corin PF $\left(t_{(21)}=2.28, p \sim 0.03\right)$, and no significant in preSMA $\left(t_{(114)}=0.21, p \sim 0.83\right)$. Also, the firing regularity expressed a significant interregional difference between the higher-order motor area (preSMA) and the PF compared to within-group variability $\left(t\right.$ test, $t_{(61)}=4.88, p<$ $\left.10^{-5}\right)$. This difference is much more prominent than firing rate $\left(t_{(29)}=-4.38, p<10^{-3}\right)$ or ISI correlation $\left(t_{(54)}=\right.$ $-1.17, p \sim 0.25$; Fig. $7 B$ ). Thus, the firing regularity is robustly specific to brain region types.

\section{Possible origin of the difference in} firing regularity across brain regions The fast-spiking interneurons are known to exhibit high firing rate rather regularly (Connors and Gutnick, 1990), and the difference in firing patterns across brain regions might be due to the difference in the population of the cell types. However, pyramidal neurons, the majority type in the cortex (Hendry et al., 1987; Abeles, 1991), can also exhibit different firing patterns due to underlying network properties. Here we attempt to explore the origin of the difference in firing regularity across brain regions.

To see the difference in firing characteristics between different cell types, we analyzed spike trains recorded from the hippocampus of rats (data set 7). In this data set, neurons were classified into putative interneurons and pyramidal neurons according to whether the duration of action potential is short or long (Sirota et al., 2008). It is observed from Figure $8 \mathrm{~A}$ that the putative interneurons exhibit the higher firing rate and regularity than those of putative pyramidal neurons, and the firing characteristics of pyramidal neurons (solid ellipse for $75 \%$ confidence region) were shifted when putative interneurons were included (dashed ellipse).

Many distributions of the mean and dispersion of the firing regularity in Figure $4 A$ are positively tilted ( 24 of 35 data sets). This may be caused by a skewed distribution of the firing regularity, because the covariance between sample mean and sample variance or dispersion is proportional to the skewness (Zhang, 2007). Positively skewed distributions of the firing regularity may be obtained if a small number of interneurons exhibit the more regular firing than a larger number of pyramidal neurons. 
Nevertheless, pyramidal neurons alone may exhibit different firing patterns in different cortical areas; we analyzed spike trains recorded from rat motor cortex (data set 1 ) and somatosensory (barrel) cortex (data set 5) recorded using a juxtacellular labeling technique, with which the recorded cells can be identified as pyramidal with morphological information. Firing regularity turned out to be significantly different between these cortical areas $\left(t\right.$ test, $t_{(60)}=7.03, p<10^{-8}$; Fig. $8 B, C)$. Firing patterns of pyramidal neurons in hippocampus, somatosensory cortex, and motor cortex are compared in Figure $8 D$, exhibiting systematic difference in firing regularity. This implies that the mean firing regularity in each brain region is mainly due to pyramidal neurons.

\section{Discussion}

Our study raised three points that merit consideration: first, as shown before, the regimes in which neuronal firing occurs exhibit systematic differences across different functional regions of the brain (Shinomoto et al., 2009); second, the firing regimes are similar across homologous regions in different species; and third, the parameter of the firing regimes strongly correlated to the functional regions is firing regularity.

Ideally, to investigate whether neurons in homologous functional brain regions have similar firing statistics across species, it would be desirable to have data from a single laboratory recording in different species under similar conditions. It is generally difficult to obtain data on physiological recordings from different species under the same conditions with the same behavior. However, we were able to compare neuronal firings recorded from two brain regions of the same monkeys performing the same task. Overall, however, we collected data obtained under a variety of conditions from several different laboratories. Our single requirement was that the data be recordings taken from experimental groups using awake animals. There is long-standing evidence that there are systematic patterns of activity that characterize the waking state (Klimesch, 1999). There is a concern that data taken from different laboratories might differ because of systematic differences in techniques across laboratories. These differences include the criteria for isolating spikes from single neurons and biases in the sampling of neurons, e.g., sampling large (likely) versus small (less likely) neurons. Because of the differences in neurophysiological technique and sampling, there might have been a large enough amount of random scatter in our measurements that we would not have seen the systematic groupings that we did identify. However, despite these potential or even probable differences, the data we examined here group nicely for our measures. Thus, even though the tasks were different across species and brain regions, it is noteworthy, perhaps even remark-
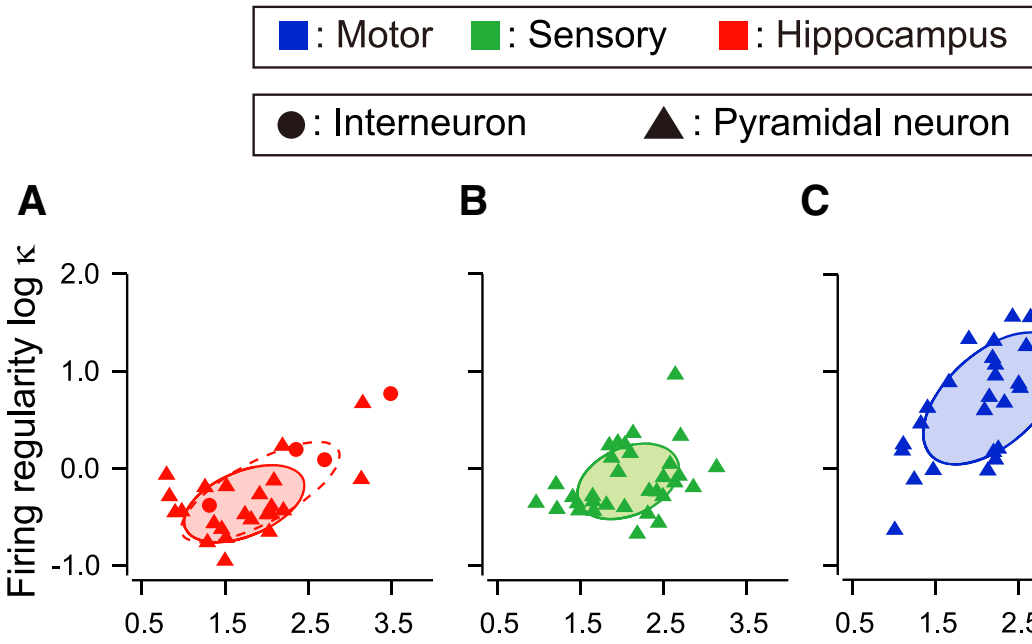

B
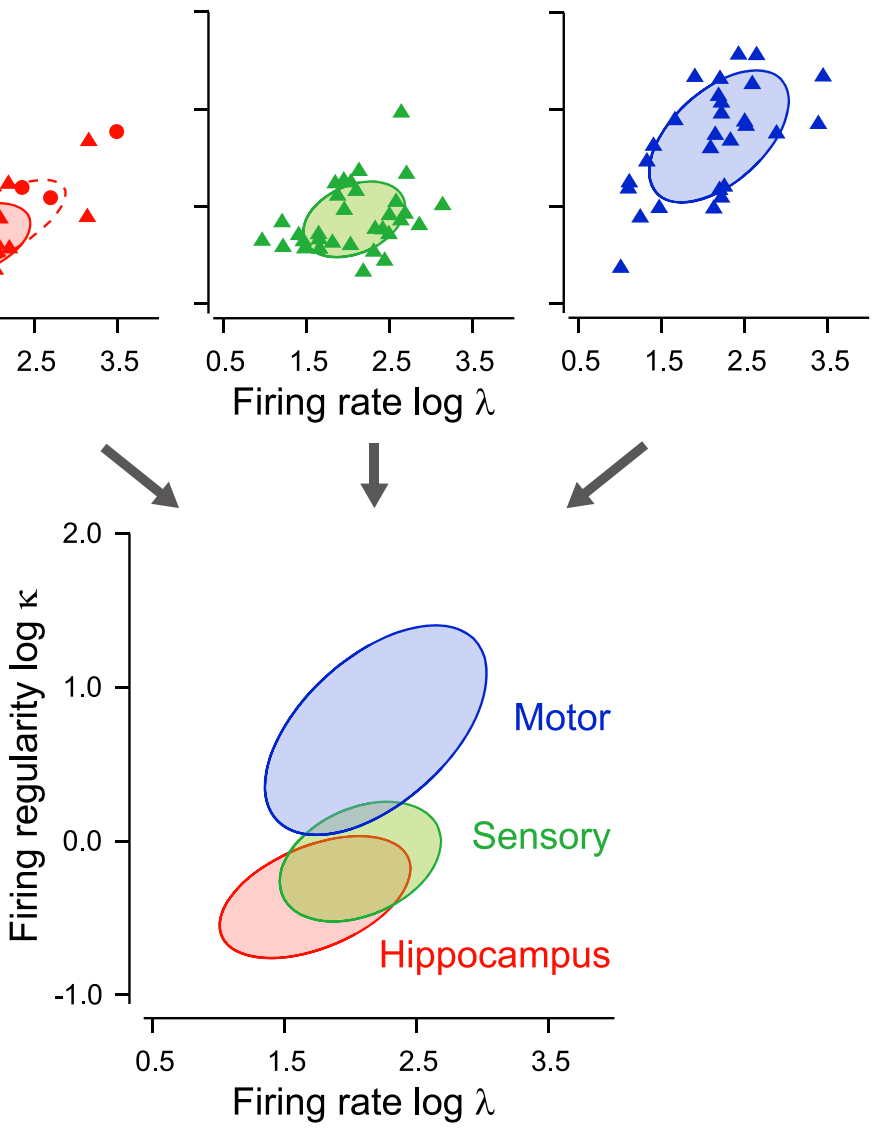

Figure 8. Distributions of firing patterns across different cell types as well as different brain regions. $A$, Firing rate and regularity of neurons in rat hippocampus. Putative interneurons and pyramidal neurons are depicted as circles and triangles. Solid and dashed ellipses represent $75 \%$ confidence regions of putative pyramidal cells and the entire data set, respectively. B, C, Firing rate and regularity of pyramidal neurons in rat somatosensory and motor cortices, identified by juxtacellular labeling. Solid ellipses represent $75 \%$ confidence regions. $\boldsymbol{D}$, Comparison of the firing patterns of pyramidal neurons across three brain regions.

able, that we see the statistical commonalities across species that we do see.

\section{Functional differentiation of firing patterns}

The differences in firing regimes across functional regions may be seen as a natural consequence of the functional subdivisions coinciding with architectonic subdivisions. It seems like different cellular and connectional organization represented by different architectonics ought to exhibit different dynamics. We have shown that putative pyramidal neurons and interneurons exhibited different firing patterns in a single brain region, whereas the pyramidal neurons themselves exhibited systematic differences in firing regularity across different brain regions.

The presence of systematic difference in firing patterns suggests that it might be possible to distinguish brain regions according to their mean and dispersion of firing regularity of sampled neurons, much as we identify cytoarchitectonic divisions by the functional tuning properties. When we used a Bayes' discrimination analysis, we found a systematic trend of grouping according to anatomical substrate (Fig. 9). When the mean and the disper- 


\section{: Motor $\quad$ : Visual $\square:$ mPFC/PF $\square:$ Hippocampus}

A

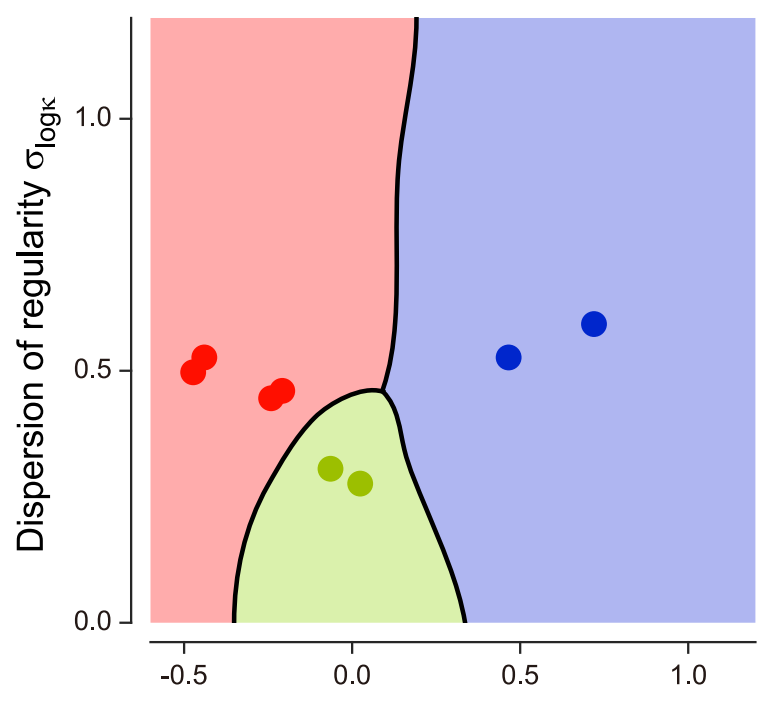

B

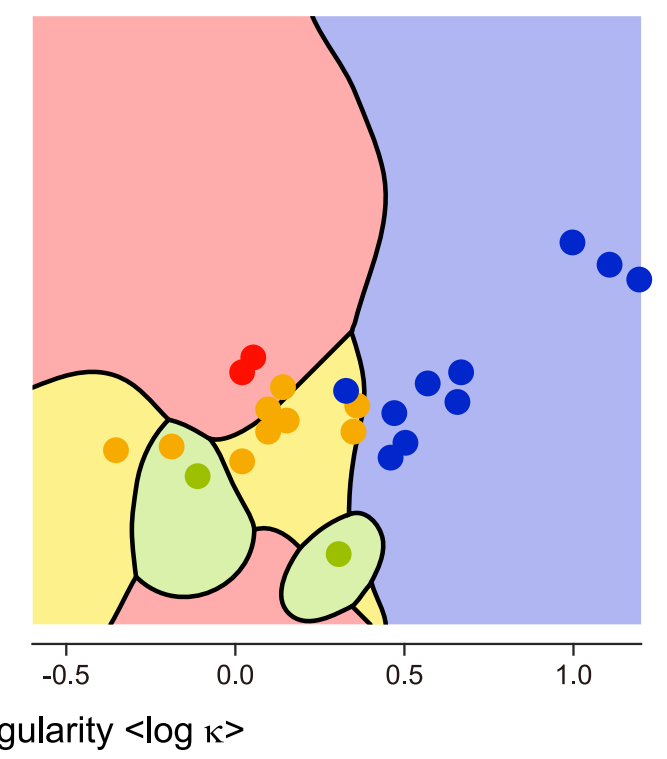

Figure 9. Discrimination of the firing regularity in terms of cortical functions. Gaussian discriminant analysis was applied to the firing regularity plane to determine the decision boundaries for the most likely cortical regions. $\boldsymbol{A}$, Rat motor cortices, mPFC, and hippocampus. $\boldsymbol{B}$, Monkey motor cortices, visual cortices, PF, and hippocampus.

sion of firing regularity were computed from 10 spike trains sampled from a single data set, the brain region was inferred correctly in 97 and 75\% of cases taken from rat and monkey, respectively. With 20 spike trains, the percentages increased to 99 and $82 \%$.

It seems unsurprising that the functional divisions based on cytoarchitectonics would have different dynamics. Neurons in each functional division send and receive unique interareal axonal projections (Felleman and Van Essen, 1991; Passingham et al., 2002) and possess specific intrinsic laminar or horizontal connections (Kritzer et al., 1992; Amir et al., 1993; Lund et al., 1993; Defelipe et al., 1999; Hooks et al., 2011). In addition, dendritic morphology and spine densities of pyramidal neurons systematically vary across the cortical areas (Elston and Rosa, 1998; Benavides-Piccione et al., 2002; Elston, 2002, 2003; BallesterosYáñez et al., 2006). Diversity in the distribution and connectivity of inhibitory interneurons across cortical regions has been reported (Kritzer et al., 1992; Defelipe et al., 1999). This variety of mechanisms could underlie the observed systematic variations in firing patterns across brain regions. We speculate that future studies that identify key mechanisms to control regularity of neuronal firing will inform us as to which organization makes coding efficient, depending on the type of information they receive.

\section{Similarity of firing patterns across animal species}

The fact that firing regimes were similar across different animal species indicates strong similarity in neuronal circuitries between homologous regions across different animals, regardless of an overwhelming difference in the brain size (Fig. 4). Our examination of interspecies similarity in the firing regimes across brain regions revealed that the mPFC of rats and the PF of monkeys were similar with respect to neuronal firing regularity, despite the controversy regarding their cytoarchitectonic homology (Uylings et al., 2003).

\section{Functional significance of firing regularity}

We searched for the firing characteristics that are essentially correlated to the functional area. In our previous study, we used an index of local variation, $L v$ (Shinomoto et al., 2003), or its variant, $L v R$ (Shinomoto et al., 2009), which are relatively independent of the firing rate that fluctuates widely according to animals' tasks. However, $L v$ or $L v R$ can be interpreted either as the ISI variability (firing regularity) or as ISI correlation (see Materials and Methods). Here, we estimated firing regularity and ISI correlation separately for each spike train and found that firing regularity was more closely related to brain region than either ISI correlation or firing rate.

Our finding that firing regularity varies systematically with brain region should spur interest in learning how regularity or irregularity influences neuronal information processing. Because different regions in the brain are specialized for different functions, it is reasonable to expect different regions are using specific code structures and that these are enforced by entering into appropriate regimes for processing different kinds of signals. Theoretical studies have suggested that the quality of information encoded might be represented by jumps among quasi-stationary states (Amit, 1989; Abeles et al., 1995; Mazzucato et al., 2015). If such transitions are mapped into the single neuron level, spike trains may be seen as bursting or irregular. At the other extreme, neurons may send real values that vary continuously in time. In this case, regular firing may be more efficient than irregular firing in transmitting real values. Considering the functional modularity of the brain, it is reasonable that neurons in different regions are in different regimes giving rise to appropriate patterns of firing (Mochizuki and Shinomoto, 2014). The next step would be to extend the analysis of single unit spike trains to the multivariate analysis of multiunit data.

The visual areas were characterized by near-Poisson statistics on average. Several authors (Elston, 2003; Maimon and Assad, 
2009; Murray et al., 2014) postulated that the visual areas are adapted to processing rapidly changing visual scenes because of smaller capacity for synaptic integration (Amir et al., 1993; Elston and Rosa, 1998; Elston, 2002, 2003) or shorter integration time (Murray et al., 2014). It is an interesting theoretical topic to investigate whether the Poisson statistics are optimal or the wider variety of firing patterns are needed for processing visual scenes. We also reported the systematic deviation from the Poisson statistics in other areas. Theoretical considerations suggest that the temporal correlations are beneficial to neural coding in two ways. First, in terms of rate coding, regular firing can be advantageous because downstream neurons achieve higher signal-to-noise ratio in counting the number of spikes that they receive (Filion and Tremblay, 1991; Bergman et al., 1994; Davies et al., 2006). The motor areas seem suitable regions for the regular patterns because downstream muscle fibers inevitably low-pass filter the presynaptic inputs from motoneurons (Maimon and Assad, 2009). Second, the temporal correlations may act as a channel of information (Pillow et al., 2008; Jacobs et al., 2009). Among the data sets we analyzed, hippocampus showed the most bursting firing on average. Consistent with the idea that the burst activity conveys information, studies using rodents showed that hippocampal burst activity appears in a context-dependent manner (Harris and Mrsic-Flogel, 2013), makes synaptic transmission reliable (Lisman, 1997), and influences plasticity (Moore et al., 1993; Takahashi and Magee, 2009).

In summary, we have shown that there are similarities across neuronal firings in similar or roughly homologous regions that are robust across the large differences in behavior used to collect the data in different experiments. The systematic deviation in firing regularity from Poisson randomness along with the robustness across species should provoke study into learning what differences in firing regularity enable different forms of information to be efficiently encoded.

\section{References}

Abeles M (1991) Corticonics: neural circuits of the cerebral cortex. New York: Cambridge UP.

Abeles M, Bergman H, Gat I, Meilijson I, Seidemann E, Tishby N, Vaadia E (1995) Cortical activity flips among quasi-stationary states. Proc Natl Acad Sci U S A 92:8616-8620. CrossRef Medline

Amir Y, Harel M, Malach R (1993) Cortical hierarchy reflected in the organization of intrinsic connections in macaque monkey visual cortex. J Comp Neurol 334:19-46. CrossRef Medline

Amit DJ (1989) Modeling brain function. Cambridge, UK: Cambridge UP. Ballesteros-Yáñez I, Benavides-Piccione R, Elston GN, Yuste R, DeFelipe J (2006) Density and morphology of dendritic spines in mouse neocortex. Neuroscience 138:403-409. CrossRef Medline

Benavides-Piccione R, Ballesteros-Yáñez I, DeFelipe J, Yuste R (2002) Cortical area and species differences in dendritic spine morphology. J Neurocytol 31:337-346. CrossRef Medline

Bergman H, Wichmann T, Karmon B, DeLong MR (1994) The primate subthalamic nucleus. II. Neuronal activity in the MPTP model of parkinsonism. J Neurophysiol 72:507-520. Medline

Bishop CM (2006) Pattern recognition and machine learning, Ed 1. New York: Springer.

Brodmann K (1909) Vergleichende lokalisationsiehre der Grosshirnrinde in ihren Prinzipien Dargestellt auf Grund des Zellenbaues. Leipzig, Germany: Verlag von Johann Ambrosius Barth.

Brown EN, Barbieri R, Ventura V, Kass RE, Frank LM (2002) The timerescaling theorem and its application to neural spike train data analysis. Neural Comput 14:325-346. CrossRef Medline

Bullock TH, Bennett MV, Johnston D, Josephson R, Marder E, Fields RD (2005) Neuroscience. The neuron doctrine, redux. Science 310:791-793. CrossRef Medline

Burns BD, Webb AC (1976) The spontaneous activity of neurones in the cat's cerebral cortex. Proc R Soc Lond B Biol Sci 194:211-223. CrossRef Medline

Connors BW, Gutnick MJ (1990) Intrinsic firing patterns of diverse neocortical neurons. Trends Neurosci 13:99-104. CrossRef Medline

Cox DR, Lewis PAW (1966) The statistical analysis of series of events. London: Methuen.

Davies RM, Gerstein GL, Baker SN (2006) Measurement of time-dependent changes in the irregularity of neural spiking. J Neurophysiol 96:906-918. CrossRef Medline

DeFelipe J (2010) From the connectome to the synaptome: an epic love story. Science 330:1198-1201. CrossRef Medline

DeFelipe J, González-Albo MC, Del Río MR, Elston GN (1999) Distribution and patterns of connectivity of interneurons containing calbindin, calretinin, and parvalbumin in visual areas of the occipital and temporal lobes of the macaque monkey. J Comp Neurol 412:515-526. CrossRef Medline

Elston GN (2002) Cortical heterogeneity: implications for visual processing and polysensory integration. J Neurocytol 31:317-335. CrossRef Medline

Elston GN (2003) Cortex, cognition and the cell: new insights into the pyramidal neuron and prefrontal function. Cereb Cortex 13:1124-1138. CrossRef Medline

Elston GN, Rosa MG (1998) Morphological variation of layer III pyramidal neurones in the occipitotemporal pathway of the macaque monkey visual cortex. Cereb Cortex 8:278-294. CrossRef Medline

Farkhooi F, Strube-Bloss MF, Nawrot MP (2009) Serial correlation in neural spike trains: experimental evidence, stochastic modeling, and single neuron variability. Phys Rev E Stat Nonlin Soft Matter Phys 79:021905. CrossRef Medline

Felleman DJ, Van Essen DC (1991) Distributed hierarchical processing in the primate cerebral cortex. Cereb Cortex 1:1-47. Medline

Filion M, Tremblay L (1991) Abnormal spontaneous activity of globus pallidus neurons in monkeys with MPTP-induced parkinsonism. Brain Res 547:142-151. Medline

Gerstein GL, Mandelbrot B (1964) Random walk models for the spike activity of a single neuron. Biophys J 4:41-68. CrossRef Medline

Harris KD, Mrsic-Flogel TD (2013) Cortical connectivity and sensory coding. Nature 503:51-58. CrossRef Medline

Hendry SH, Schwark HD, Jones EG, Yan J (1987) Numbers and proportions of GABA-immunoreactive neurons in different areas of monkey cerebral cortex. J Neurosci 7:1503-1519. Medline

Holt GR, Softky WR, Koch C, Douglas RJ (1996) Comparison of discharge variability in vitro and in vivo in cat visual cortex neurons. J Neurophysiol 75:1806-1814. Medline

Hooks BM, Hires SA, Zhang YX, Huber D, Petreanu L, Svoboda K, Shepherd GM (2011) Laminar analysis of excitatory local circuits in vibrissal motor and sensory cortical areas. PLoS Biol 9:e1000572. CrossRef Medline

Jacobs AL, Fridman G, Douglas RM, Alam NM, Latham PE, Prusky GT, Nirenberg S (2009) Ruling out and ruling in neural codes. Proc Natl Acad Sci U S A 106:5936-5941. CrossRef Medline

Klimesch W (1999) EEG alpha and theta oscillations reflect cognitive and memory performance: a review and analysis. Brain Res Rev 29:169-195. CrossRef Medline

Kritzer MF, Cowey A, Somogyi P (1992) Patterns of inter- and intralaminar GABAergic connections distinguish striate (V1) and extrastriate (V2, V4) visual cortices and their functionally specialized subdivisions in the rhesus monkey. J Neurosci 12:4545-4564. Medline

Kuffler SW, Fitzhugh R, Barlow HB (1957) Maintained activity in the cat's retina in light and darkness. J Gen Physiol 40:683-702. CrossRef Medline

Lisman JE (1997) Bursts as a unit of neural information: making unreliable synapses reliable. Trends Neurosci 20:38-43. CrossRef Medline

Lund JS, Yoshioka T, Levitt JB (1993) Comparison of intrinsic connectivity in different areas of macaque monkey cerebral cortex. Cereb Cortex 3:148-162. CrossRef Medline

Maimon G, Assad JA (2009) Beyond Poisson: increased spike-time regularity across primate parietal cortex. Neuron 62:426-440. CrossRef Medline

Mazzucato L, Fontanini A, La Camera G (2015) Dynamics of multistable states during ongoing and evoked cortical activity. J Neurosci 35: 8214-8231. CrossRef Medline

Mita A, Mushiake H, Shima K, Matsuzaka Y, Tanji J (2009) Interval time coding by neurons in the presupplementary and supplementary motor areas. Nat Neurosci 12:502-507. CrossRef Medline

Miura K, Okada M, Amari S (2006) Estimating spiking irregularities under changing environments. Neural Comput 18:2359-2386. CrossRef Medline 
Mochizuki Y, Shinomoto S (2014) Analog and digital codes in the brain. Phys Rev E Stat Nonlin Soft Matter Phys 89:022705. CrossRef Medline

Moore CI, Browning MD, Rose GM (1993) Hippocampal plasticity induced by primed burst, but not long-term potentiation, stimulation is impaired in area CA1 of aged Fischer 344 rats. Hippocampus 3:57-66. CrossRef Medline

Murray JD, Bernacchia A, Freedman DJ, Romo R, Wallis JD, Cai X, PadoaSchioppa C, Pasternak T, Seo H, Lee D, Wang XJ (2014) A hierarchy of intrinsic timescales across primate cortex. Nat Neurosci 17:1661-1663. CrossRef Medline

Northcutt RG, Kaas JH (1995) The emergence and evolution of mammalian neocortex. Trends Neurosci 18:373-379. CrossRef Medline

Passingham RE, Stephan KE, Kötter R (2002) The anatomical basis of functional localization in the cortex. Nat Rev Neurosci 3:606-616. CrossRef Medline

Pillow JW, Shlens J, Paninski L, Sher A, Litke AM, Chichilnisky EJ, Simoncelli EP (2008) Spatio-temporal correlations and visual signalling in a complete neuronal population. Nature 454:995-999. CrossRef Medline

Ramón y Cajal S (1899) Textura del sistema nervioso del hombre y de los vertebrados, Ed 1. Madrid: Nicolas Moya.

Reich DS, Victor JD, Knight BW (1998) The power ratio and the interval map: spiking models and extracellular recordings. J Neurosci 18:1009010104. Medline

Shimokawa T, Shinomoto S (2009) Estimating instantaneous irregularity of neuronal firing. Neural Comput 21:1931-1951. CrossRef Medline

Shinomoto S, Shima K, Tanji J (2003) Differences in spiking patterns among cortical neurons. Neural Comput 15:2823-2842. CrossRef Medline
Shinomoto S, Kim H, Shimokawa T, Matsuno N, Funahashi S, Shima K, Fujita I, Tamura H, Doi T, Kawano K, Inaba N, Fukushima K, Kurkin S, Kurata K, Taira M, Tsutsui K, Komatsu H, Ogawa T, Koida K, Tanji J, et al. (2009) Relating neuronal firing patterns to functional differentiation of cerebral cortex. PLoS Comput Biol 5:e1000433. CrossRef Medline

Sirota A, Montgomery S, Fujisawa S, Isomura Y, Zugaro M, Buzsáki G (2008) Entrainment of neocortical neurons and gamma oscillations by the hippocampal theta rhythm. Neuron 60:683-697. CrossRef Medline

Softky WR, Koch C (1993) The highly irregular firing of cortical cells is inconsistent with temporal integration of random EPSPs. J Neurosci 13: 334-350. Medline

Stein RB (1965) A theoretical analysis of neuronal variability. Biophys J 5:173-194. CrossRef Medline

Takahashi H, Magee JC (2009) Pathway interactions and synaptic plasticity in the dendritic tuft regions of CA1 pyramidal neurons. Neuron 62:102111. CrossRef Medline

Toga AW, Thompson PM, Mori S, Amunts K, Zilles K (2006) Towards multimodal atlases of the human brain. Nat Rev Neurosci 7:952-966. CrossRef Medline

Uylings HB, Groenewegen HJ, Kolb B (2003) Do rats have a prefrontal cortex? Behav Brain Res 146:3-17. CrossRef Medline

Werner G, Mountcastle VB (1963) The variability of central neural activity in a sensory system and its implication for the central reflection of sensory events. J Neurophysiol 26:958-977. Medline

Zhang L (2007) Sample mean and sample variance. Am Statist 61:159-160. CrossRef

Zilles K, Amunts K (2010) Centenary of Brodmann's map-conception and fate. Nat Rev Neurosci 11:139-145. CrossRef Medline 